\title{
The Comparative Effects of Listening to Prayer Recitation and Music Therapy Intraoperatively on Postoperative Pain
}

\author{
Farah Syaza Rahman ${ }^{\mathrm{a}}$ Nurlia Yahya ${ }^{\mathrm{a}}$, Nor Mohammad Md Din ${ }^{\mathrm{b}}$, Azarinah Izaham ${ }^{\mathrm{a}}$ Wan Rahiza Wan Mat ${ }^{\mathrm{a}}$ \\ ${ }^{a}$ Department of Anaesthesiology \& Intensive Care, Universiti Kebangsaan Malaysia Medical Center (UKMMC), \\ Jalan Yaacob Latif, Bandar Tun Razak 56000 Kuala Lumpur, Malaysia. \\ ${ }^{b}$ Department of Anaesthesia \& Intensive Care, Kuala Lumpur General Hospital, Jalan Pahang, 53000 Kuala \\ Lumpur, Malaysia.
}

\section{ABSTRACT}

Introduction: Non-pharmacological interventions are considered as successful adjuncts to manage pain. We are studying the comparative effects of listening to prayer recitation and music therapy intraoperatively as non-pharmacological interventions on postoperative pain and intraoperative haemodynamics. Materials and Methods: Seventy two muslim patients with acute appendicitis requiring open, emergency appendicectomies under general anaesthesia were recruited and randomised into three groups: Group A: patients who listened to prayer recitation, Group B: patients who listened to music, Group C: control group - patients who did not listen to any prayer or music. Intraoperative blood pressure, heart rate and postoperative pain scores were monitored. Results: The demographic data, pre- and post-headphones application haemodynamics were compared. There were significantly lower heart rates at 10, 20, 30, 40, 50, 60 minutes for Group A and at 50 and 60 minutes for Group B patients when compared to Group C. Significant reduction in postoperative pain scores were seen in Group A patients at 30 minutes and 8 hours as compared to Group $C$ patients. No significant differences in pain scores were seen between Group B and C patients. No significant differences in additional analgesic requirements postoperatively were seen in all three groups. Conclusion: Listening to prayer recitation or music intraoperatively significantly lowered intraoperative heart rates, however only prayer recitation significantly reduced postoperative pain scores as compared to the control group.

KEYWORDS: postoperative pain, music therapy, prayer, pain scores.

\section{INTRODUCTION}

Approximately $80 \%$ of patients experienced acute pain after surgery despite our current advances of pain management. ${ }^{1}$ The knowledge of molecular mechanisms of pain has led to the development of multimodal analgesia, combining pharmacological and non-pharmacological interventions. Pharmacological interventions are widely used however they are not free from side effects. Almost $25 \%$ of patients receiving pain

Corresponding author:

Dr. Nurlia Yahya,

Department of Anesthesiology \& Intensive Care, UKMMC, Jalan Yaacob Latif, Bandar Tun Razak,Cheras, 56000 Kuala Lumpur Malaysia .

Tel no : +6039145 5783

Fax no: +60391456585

email: nurlia@ppukm.ukm.edu.my medications experienced side-effects. ${ }^{1}$ Although non -pharmacological interventions are not meant to replace pharmacological interventions, treatments that combine different approaches, such as psychological, spiritual and alternative therapies are often considered successful adjuncts in treating and managing acute to chronic pain. ${ }^{2}$ One of the psychological and spiritual non-pharmacological means of interventions is listening to prayer recitation. A study by Nasiri et al on the effects of reciting the word "Allah" on pain severity after coronary artery bypass reported a significant reduction of pain severity in the first three days after surgery. ${ }^{3}$ Another study by Beiranvand et al on the effects of prayer meditation on postoperative pain and anxiety showed that there was significant reduction of postoperative pain in caesarean section patients. ${ }^{4}$ Another non-pharmacological means of pain intervention is music therapy. A study by Jha et 
al found that rescue analgesia given in the first 24 hours postoperatively was significantly less in patients receiving music therapy intraoperatively as compared to those who did not. ${ }^{5}$

Besides pain, postoperative nausea and vomiting (PONV) is a major concern for patients who present for surgery. PONV is a common cause of patient dissatisfaction after anaesthesia, with reported incidence of $30 \%$ in all post-surgical patients and up to $80 \%$ in high-risk patients. ${ }^{6,7}$ Besides pain control, a reduction of PONV has also been demonstrated in patients who listened to prayer recitation and music intraoperatively. Beiranvand et al demonstrated a reduction of incidence of PONV in patients who had undergone caesarean section under spinal anaesthesia with prayer meditation and Jayamaran et al has demonstrated a reduction of incidence of PONV in patients receiving music therapy under general anaesthesia. ${ }^{4,8}$

Studies have suggest that auditory processing remains active under general anaesthesia. ${ }^{9-11}$ Block et al conducted postoperative implicit memory tests on patients who listened to intraoperative suggestions after induction of general anaesthesia. The tests included Behavioural Suggestions Test, Word Completion Test and Nonsense Word Test and they concluded that auditory function was preserved and some information processing functions of the brain evidently continued to function during adequate general anaesthesia. ${ }^{10}$ Jayamaran et al conducted a study on how music therapy affects postoperative parameters under general anaesthesia and showed that therapeutic music enables the patient to be in a more positive frame of mind and also affects various recovery parameters in the postoperative period like pain, fatigue, psychological well-being, nausea and vomiting, and thus ultimately the postoperative outcome of patients. ${ }^{8}$

\section{METHODS}

This prospective randomised, double-blinded clinical trial was conducted after obtaining approval from the Research Committee of the Department of Anaesthesiology and Intensive Care, Universiti Kebangsaan Malaysia Medical Centre, the Universiti Kebangsaan Malaysia Medical Research and Ethics Committee (FF-2017-095) and the Medical Research and Ethics Committee, Ministry of Health Malaysia, (NMRR-16-2368-33083). Muslim patients aged between 18 and 65 years old with American Society of Anesthesiologists (ASA) physical status I or II, diagnosed with acute appendicitis requiring emergency open appendicectomy using a Lanz incision under general anaesthesia were recruited in this study. Patients with hearing disabilities, psychiatric illness, neurological disorders or with a past history of chronic pain and those on regular analgesics were excluded from this study.

Patients were recruited on the day of surgery. Explanation of the study and written consent were obtained by the primary investigator. Patients were fasted for at least 6 hours before surgery. Randomisation was done in the reception area. Patients were randomised into three groups, using computer generated randomised numbers into Groups A, B and C. Patients in all three groups were put on headphones intraoperatively. Group A patients listened to continuous prayer recitations which included the salawat syifa' and dzikir. Group $B$ patients listened to sounds of nature which included sounds of the waterfall and chirping birds as part of music therapy and Group $C$ was the control group whereby patients neither listened to prayer recitations nor music.

In the operating room, intravenous access was obtained using an $18 \mathrm{G}$ cannula for all patients. Standard anaesthesia monitoring with continuous electrocardiography (ECG), non-invasive blood pressure monitoring (NIBP), pulse oximetry and capnography were used. Patients' baseline heart rate, systolic blood pressure, diastolic blood pressure and mean arterial pressure were recorded prior to induction of general anaesthesia, then subsequently prior to application of the headphones and at 10 minute intervals thereafter until the end of surgery. After preoxygenation for three minutes, patients were induced via rapid sequence induction with intravenous (IV) fentanyl $2 \mathrm{mcg} / \mathrm{kg}$, IV propofol $2 \mathrm{mg} / \mathrm{kg}$, IV suxamethonium $1.5 \mathrm{mg} / \mathrm{kg}$ and intubated with an appropriate sized endotracheal tube. Muscle relaxation was maintained with either IV rocuronium or atracurium and anaesthesia maintained with sevoflurane in a $50 \%: 50 \%$ combination of oxygen mixed with air. Sevoflurane concentration were adjusted to attain a Minimum Alveolar Concentration (MAC) of 0.8-1.0 throughout surgery. 
For good hygiene practice, the headphones were cleaned with alcohol swabs before being put on to the patients. Patients in all three groups were put on headphones connected to an MP3 player (a digital audio player which is a portable electronic device that can play digital audio files) immediately after induction of anaesthesia by the primary investigator. The MP3 players were played continuously and repeatedly from the start of surgery until the end of skin closure. The MP3 players used had no digital display and were colour coded, to ensure that the attending anaesthetist remained blinded throughout the surgery. The MP3 players were checked by the anaesthetic nurse at 15 minute intervals to ensure that it played continuously, except for the MP3 player for Group C patients.

Intravenous morphine $0.1 \mathrm{mg} / \mathrm{kg}$ was given for intraoperative analgesia. Additional analgesia of IV fentanyl $50 \mathrm{mcg}$ boluses were given intermittently when required and the total dosage administered was recorded. Patients who unexpectedly developed surgical perioperative complications that required extension of skin surgical incision and manipulation were dropped out from this study. Local anaesthetic infiltration was given at the surgical site at the end of surgery. After completion of surgery, neuromuscular relaxation was reversed with IV neostigmine $0.05 \mathrm{mg} / \mathrm{kg}$ and IV atropine $0.02 \mathrm{mg} / \mathrm{kg}$.

Patients were transferred to the recovery bay where their heart rate, blood pressure and oxygen saturation were measured at regular intervals as per institutional protocol. The patients' pain and PONV scores were assessed 30 minutes postoperatively by the recovery nurses. The pain score was assessed using the Numeric Rating Scale; where $0=$ no pain, scores 1 to $3=$ mild pain, 4 to 7 $=$ moderate pain and 8 to $10=$ severe pain. Patients were also assessed for PONV using the PONV 4 grade scale; where $1=$ no nausea, $2=$ mild nausea, $3=$ moderate nausea and $4=$ severe nausea.

Rescue treatment of IV fentanyl 50 mcg was given for patients with pain scores of 4 and above while IV ondansetron $4 \mathrm{mg}$ was given for patients with moderate to severe nausea. Patients were discharged to the ward once the pain scores were 3 and below, PONV scale 2 and below and the standard discharge criteria were met. In the ward, blood pressure, heart rate, pain and PONV scores at 4, 8, 12 and 24 hours post-surgery were recorded by the ward nurses. All patients were routinely prescribed with oral paracetamol $1 \mathrm{~g} 6$ hourly and oral diclofenac sodium $50 \mathrm{mg} 8$ hourly for postoperative analgesia. IV tramadol $50 \mathrm{mg} 8$ hourly was given if patients were still in pain.

The sample size was calculated using the PASS (Power Analysis \& Sample Size System) software using the independent $\mathrm{t}$-test based on the mean pain scores and standard deviation as quoted in Beiranvand et al. ${ }^{4}$ The power of this study was set at $95 \%$, a-value of 0.05 and standard deviation of 1.3 . Twenty one patients were calculated for each group. Anticipating a 10\% drop- out rate, 24 patients were eventually recruited in each group, with a total of 72 patients required for the study. The data was analysed using the IBM Corp. SPSS Statistics for Windows, Version 20 Armonk, NY: IBM Corp. ShapiroWilks test was used to test the assumption of normality. One way analysis of variance (ANOVA) and Tukey HSD test were used to determine whether there were any statistically significant differences between mean blood pressures and mean heart rates. Kruskal-Wallis test was used to calculate any significant difference in median for non-parametric data which included age, pain scores and PONV scales. Further post-hoc analysis was done using Mann-Whitney $U$ test with Bonferroni correction $(p<0.025)$.

Fisher exact test was used to calculate any significant differences for gender and ASA between groups. A $p$ value of less than 0.05 was considered statistically significant. This study compared the results of Group A versus C and Group B versus C. We did not directly compare Group A versus $B$ in view of 'aqidah' (religious beliefs) sensitivities.

\section{RESULTS}

A total of 72 patients were recruited into this study. No patients dropped out of the study. There were no significant differences in the demographic data and the mean duration of surgery among the three groups as shown in Table I. 
Table I. Demographic data.

\begin{tabular}{|c|c|c|c|c|c|}
\hline & & $\begin{array}{c}\text { Group } A \\
(n=24)\end{array}$ & $\underset{(n=24)}{\operatorname{Group}} B$ & $\underset{(n=24)}{\operatorname{Group}} \mathrm{C}$ & $p$ value \\
\hline \multicolumn{2}{|c|}{ Age (Years) } & *22.5 (20.0-27.7) & *26 (20.3-32.0) & *26 (22.0-31.5) & 0.294 \\
\hline Gender & $\begin{array}{r}\text { Male } \\
\text { Female }\end{array}$ & $\begin{array}{ll}* * 12 & (50.0) \\
* * 12 & (50.0)\end{array}$ & $\begin{array}{l}* * 15(62.4) \\
* * 9(37.5)\end{array}$ & $\begin{array}{l}{ }^{* *} 16(66.7) \\
{ }^{* *} 8(33.3)\end{array}$ & 0.568 \\
\hline ASA & I & $\begin{array}{l}* * 22(91.7) \\
* * 2(8.3)\end{array}$ & $\begin{array}{l}{ }^{* *} 18(75.0) \\
{ }^{* *} 6(25.0)\end{array}$ & $\begin{array}{l}* * 22(91.7) \\
* * 2(8.3)\end{array}$ & 0.195 \\
\hline \multicolumn{2}{|c|}{ Duration of Surgery (Minutes) } & ${ }^{\#} 52.6 \pm 16.9$ & ${ }^{\#} 59.6 \pm 18.1$ & ${ }^{\#} 59.6 \pm 18.5$ & 0.303 \\
\hline
\end{tabular}

Values are expressed as *median (interquartile range), ${ }^{* *}$ numbers (percentage) and ${ }^{*}$ mean \pm SD

The intraoperative arterial pressures expressed as mean for all three groups are shown in Table II. At 50 minutes intraoperatively, there was a significant reduction of mean arterial pressure for Group A as compared to Group $C$ patients. The rest of the mean arterial pressures were comparable. The results were tabulated up to 80 minutes only because majority of the patients completed their surgery within 80 minutes. Only one patient from Group A and two from Groups B and $C$ respectively underwent surgery beyond 80 minutes, in which the maximum duration of surgery was 100 minutes. Further analysis with the post hoc test could not be performed beyond 80 minutes due to the small number of patients.

Table II. Intraoperative mean arterial pressures $(\mathrm{mmHg})$.

\begin{tabular}{|c|c|c|c|c|c|}
\hline Time (Minutes) & Group A & Group B & Group C & $p$ value $^{a}$ & $\begin{array}{c}\text { Comparison of } \\
\text { value }^{\mathrm{b}}\end{array}$ \\
\hline Pre-induction & $\begin{array}{c}89.04 \pm 13.46 \\
(n=24)\end{array}$ & $\begin{array}{c}92.54 \pm 16.03 \\
(n=24)\end{array}$ & $\begin{array}{c}90.25 \pm 12.31 \\
(n=24)\end{array}$ & 0.681 & \\
\hline Pre-headphone & $\begin{array}{c}77.83 \pm 12.64 \\
(24)\end{array}$ & $\begin{array}{c}84.25 \pm 17.83 \\
(24)\end{array}$ & $\begin{array}{c}87.16 \pm 12.16 \\
(24)\end{array}$ & 0.080 & \\
\hline 10 & $\begin{array}{c}76.50 \pm 9.26 \\
(24)\end{array}$ & $\begin{array}{c}77.29 \pm 12.31 \\
(24)\end{array}$ & $\begin{array}{c}79.54 \pm 12.49 \\
(24)\end{array}$ & 0.636 & \\
\hline 20 & $\begin{array}{c}74.09 \pm 13.00 \\
(24)\end{array}$ & $\begin{array}{c}82.37 \pm 13.99 \\
(24)\end{array}$ & $\begin{array}{c}79.45 \pm 8.0 \\
(24)\end{array}$ & 0.636 & \\
\hline 30 & $\begin{array}{c}78.17 \pm 11.24 \\
(24)\end{array}$ & $\begin{array}{c}82.88 \pm 10.09 \\
(24)\end{array}$ & $\begin{array}{c}80.54 \pm 6.45 \\
(24)\end{array}$ & 0.235 & \\
\hline 40 & $\begin{array}{c}75.86 \pm 8.52 \\
(21)\end{array}$ & $\begin{array}{c}80.05 \pm 10.16 \\
(22)\end{array}$ & $\begin{array}{c}80.65 \pm 8.92 \\
(23)\end{array}$ & 0.187 & \\
\hline 50 & $\begin{array}{c}74.44 \pm 7.31 \\
(18)\end{array}$ & $\begin{array}{c}80.40 \pm 10.79 \\
(20)\end{array}$ & $\begin{array}{c}81.94 \pm 9.45 \\
(19)\end{array}$ & 0.044 & $\begin{array}{l}\text { A vs C } 0.047^{*} \\
B \text { vs C } 0.864\end{array}$ \\
\hline 60 & $\begin{array}{c}77.50 \pm 6.65 \\
(10)\end{array}$ & $\begin{array}{c}82.71 \pm 9.07 \\
(13)\end{array}$ & $\begin{array}{c}81.54 \pm 7.82 \\
(14)\end{array}$ & 0.288 & \\
\hline 70 & $\begin{array}{c}77.33 \pm 3.67 \\
(6)\end{array}$ & $\begin{array}{c}85.83 \pm 10.30 \\
(7)\end{array}$ & $\begin{array}{c}79.71 \pm 10.63 \\
(6)\end{array}$ & 0.262 & \\
\hline 80 & $\begin{array}{c}72.67 \pm 4.04 \\
(3)\end{array}$ & $\begin{array}{c}84.20 \pm 10.73 \\
(4)\end{array}$ & $\begin{array}{c}75.50 \pm 5.51 \\
(5)\end{array}$ & 0.155 & \\
\hline
\end{tabular}

Values expressed in mean \pm SD and number in parenthesis. ( $n$ = Sample size), ${ }^{a} p$ value using ANOVA test, ${ }^{b} p$ value using post hoc Tukey HSD test, *statistically significant 
There were no significant differences of the mean pre-induction and pre-headphones applications heart rates in all three groups. However, there were significantly lower heart rates at 10, 20, 30, 40, 50 and 60 minutes for Group A

Table III. Intraoperative heart rates (beats per minute)

\begin{tabular}{|c|c|c|c|c|c|}
\hline Time (minutes) & Group A & Group B & Group C & $p$ value ${ }^{\mathrm{a}}$ & $\begin{array}{c}\text { Comparison of } p \\
\text { value }^{\mathrm{b}}\end{array}$ \\
\hline Pre-induction & $89.42 \pm 16.93(24)$ & $\begin{array}{c}90.08 \pm 15.98 \\
(24)\end{array}$ & $\begin{array}{c}98.37 \pm 17.84 \\
(24)\end{array}$ & 0.132 & \\
\hline Pre-headphone & $\begin{array}{c}91.13 \pm 16.11 \\
(24)\end{array}$ & $\begin{array}{c}84.54 \pm 13.62 \\
(24)\end{array}$ & $\begin{array}{c}95.13 \pm 15.91 \\
(24)\end{array}$ & 0.059 & \\
\hline 10 & $\begin{array}{c}76.83 \pm 13.11 \\
(24)\end{array}$ & $\begin{array}{c}82.79 \pm 13.15 \\
(24)\end{array}$ & $\begin{array}{c}88.33 \pm 15.90 \\
(24)\end{array}$ & $0.023^{*}$ & $\begin{array}{l}\text { A vs C } 0.017^{*} \\
\text { B vs C } 0.367\end{array}$ \\
\hline 20 & $\begin{array}{c}74.42 \pm 13.07 \\
(24)\end{array}$ & $\begin{array}{c}80.25 \pm 11.70 \\
(24)\end{array}$ & $\begin{array}{c}87.04 \pm 15.69 \\
(24)\end{array}$ & $0.008^{*}$ & $\begin{array}{l}\text { A vs C } 0.006^{*} \\
\text { B vs C } 0.201\end{array}$ \\
\hline 30 & $\begin{array}{c}71.71 \pm 11.68 \\
(24)\end{array}$ & $\begin{array}{c}77.92 \pm 11.99 \\
(24)\end{array}$ & $\begin{array}{c}84.71 \pm 14.9 \\
(24)\end{array}$ & $0.004^{*}$ & $\begin{array}{l}\text { A vs C } 0.02^{*} \\
\text { B vs C } 0.171\end{array}$ \\
\hline 40 & $\begin{array}{c}72.19 \pm 11.42 \\
(21)\end{array}$ & $\begin{array}{c}76.22 \pm 12.99 \\
(22)\end{array}$ & $\begin{array}{c}84.70 \pm 15.46 \\
(23)\end{array}$ & $0.010^{*}$ & $\begin{array}{l}\text { A vs C } 0.009^{*} \\
\text { B vs C } 0.096\end{array}$ \\
\hline 50 & $\begin{array}{c}70.61 \pm 10.94 \\
\quad(18)\end{array}$ & $\begin{array}{c}75.15 \pm 11.29 \\
(20)\end{array}$ & $\begin{array}{c}87.11 \pm 13.88 \\
(19)\end{array}$ & $0.000^{*}$ & $\begin{array}{l}\text { A vs C } 0.000^{*} \\
\text { B vs C } 0.009^{*}\end{array}$ \\
\hline 60 & $\begin{array}{c}74.80 \pm 9.28 \\
(10)\end{array}$ & $\begin{array}{c}73.86 \pm 10.83 \\
(13)\end{array}$ & $\begin{array}{c}93.07 \pm 12.98 \\
(14)\end{array}$ & $0.000^{*}$ & $\begin{array}{l}\text { A vs C } 0.001^{*} \\
\text { B vs C } 0.000^{*}\end{array}$ \\
\hline 70 & $\begin{array}{c}79.00 \pm 8.07 \\
(6)\end{array}$ & $\begin{array}{c}73.67 \pm 13.47 \\
(7)\end{array}$ & $\begin{array}{c}90.57 \pm 14.30 \\
(6)\end{array}$ & 0.068 & \\
\hline 80 & $\begin{array}{c}81.00 \pm 6.56 \\
(3)\end{array}$ & $\begin{array}{c}70.80 \pm 10.03 \\
\text { (4) }\end{array}$ & $\begin{array}{c}88.00 \pm 16.63 \\
\text { (5) }\end{array}$ & 0.157 & \\
\hline
\end{tabular}

Values expressed in mean $\pm S D$ and number in parenthesis, (Sample Size), ${ }^{a} p$ value using ANOVA test, $p$ value using post hoc Tukey HSD test, *statistically significant

As shown in Table IV, there was a significant reduction of postoperative pain scores in Group $A$ patients at 30 minutes (on movement) and 8 hours (at rest and on movement) as compared to Group C patients postoperatively. No significant differences in pain scores were seen between Group B and C patients. None of the patients in all three groups as compared to Group C patients as shown in Table III. There were also significant heart rate reductions at 50 and 60 minutes for Group B patients as compared to Group C. 
Table IV. Postoperative pain scores and number of patients who required additional postop. analgesia.

\begin{tabular}{|c|c|c|c|c|c|}
\hline Pain scores & $\underset{(n=24)}{\operatorname{Group} A}$ & $\underset{(n=24)}{\operatorname{Group} B}$ & $\underset{(n=24)}{\operatorname{Group} C}$ & $p$ value $^{a}$ & $\begin{array}{c}\text { Comparison of } \\
p \text { value }^{b}\end{array}$ \\
\hline $\begin{array}{l}30 \text { minutes } \\
\text { At rest }\end{array}$ & $3(3-2)$ & $3(4-2)$ & $3(5-3)$ & 0.091 & \\
\hline Movement & $3(3-2)$ & $3(4-3)$ & $4(5-3)$ & 0.027 & $\begin{array}{l}\text { A vs } C 0.007^{*} \\
B \text { vs } C 0.087\end{array}$ \\
\hline $\begin{array}{l}4 \text { hours } \\
\text { At rest } \\
\text { Movement }\end{array}$ & $\begin{array}{l}3(4-2) \\
3(4-2)\end{array}$ & $\begin{array}{l}4(5-2) \\
4(4-2)\end{array}$ & $\begin{array}{l}3(4-2) \\
3(4-3)\end{array}$ & $\begin{array}{l}0.138 \\
0.138\end{array}$ & \\
\hline $\begin{array}{l}8 \text { Hours } \\
\text { At rest }\end{array}$ & $2(3-1)$ & $3(3-2)$ & $3(4-2)$ & 0.024 & $\begin{array}{l}\text { A vs C } 0.011^{*} \\
\text { B vs C } 0.457\end{array}$ \\
\hline Movement & $2(3-1)$ & $3(3-2)$ & $3(4-3)$ & 0.024 & $\begin{array}{l}\text { A vs C } 0.011^{*} \\
\text { B vs C } 0.457\end{array}$ \\
\hline 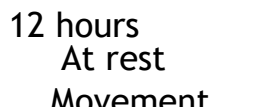 & $2(2-1)$ & $2(2-1)$ & $2(3-1)$ & 0.052 & \\
\hline $\begin{array}{l}24 \text { hours } \\
\text { At rest } \\
\text { Movement }\end{array}$ & $\begin{array}{l}1(2-1) \\
1(2-1)\end{array}$ & $\begin{array}{l}1(2-1) \\
1(2-1)\end{array}$ & $\begin{array}{l}2(2-1) \\
2(2-1)\end{array}$ & $\begin{array}{l}0.245 \\
0.212\end{array}$ & \\
\hline $\begin{array}{l}\text { No.of patients } \\
\text { who required } \\
\text { tramadol (\%) }\end{array}$ & $1(4)$ & $6(25)$ & $4(17)$ & 0.161 & \\
\hline
\end{tabular}

\section{DISCUSSION AND CONCLUSION}

Listening to either prayer recitation or music has been proven to reduce anxiety and to improve heart rate and blood pressure. ${ }^{12,13}$ The mechanism of these reductions in heart rate and blood pressure is believed to be due to the enhanced parasympathetic activity in patients listening to music. Okada et al did a study and found that music therapy enhances parasympathetic activity and decreases congestive heart failure by reducing plasma cytokine and catecholamine levels. ${ }^{14} \mathrm{~A}$ study conducted by Riganello et al looked at how music could influence autonomic nervous system response in patients with severe disorder of consciousness and they found that there were significant differences in heart rate variability parameters, characterized generally by lowered values in vegetative state/unresponsive wakefulness syndrome patients. ${ }^{15}$

Our results showed a significantly lower heart rate in the group of patients who listened to prayer recitation intraoperatively as compared to the control group, however with no difference seen in the mean arterial pressure. This finding is similar to the study conducted by Nasiri et al on the effect of reciting the word "Allah" on the vital signs of patients after a coronary artery bypass graft surgery, where they found a statistically significant reduction of heart rate $(p<0.01)$ but also found no significant changes in the systolic and diastolic blood pressure after intervention. ${ }^{3}$ We also found that there was also a significant reduction of heart rate observed at the end of surgery in patients who listened to sounds of nature intraoperatively as compared to the control group. These findings are similar to a study by Tsuchiya et al who found that listening to relaxing intraoperative sounds of nature blunts the haemodynamic changes during emergence in laparoscopic surgery patients. ${ }^{12}$ They found that the differences in heart rate and mean arterial pressures were only seen during emergence, and no difference was seen during surgery.

Our study showed that postoperative pain scores were significantly lowered in Group A patients as compared to the control group. These findings were similar to a study conducted by Beiranvand et al, where they examined the effects of listening to prayer meditation on pain intensity after caesarean section surgery under spinal anaesthesia. They found that there was significantly lower pain scores in patients who listened to prayer meditations as 
compared to the control group. ${ }^{4}$ Haryani et al did a similar study on 50 post-surgical patients, where patients were asked to recite prayer therapy postoperatively, and they found significantly lowered mean pain scores seen in patients who recited prayer therapy as compared to the control group. ${ }^{16}$

Many studies have shown that music therapy is effective in reducing pain scores as an adjunct to pharmacological therapy. ${ }^{5,8,17}$ Jayamaran et al studied on the effects of calm and relaxing music therapy and positive therapeutic suggestions during general anaesthesia in patients who underwent laparoscopic cholecystectomy under general anaesthesia, and found significant improvement of pain scores and postoperative nausea and vomiting. ${ }^{8}$ Jha et al did a similar study using sounds of nature with additional relaxing and encouraging verbal suggestions, and found a significant reduction of analgesic requirements in patients who listened to music intraoperatively as compared to the control group. ${ }^{5}$ However, our study showed no statistically significant reduction in pain scores for patients who listened to sounds of nature intraoperatively. This could possibly be due to the selection of music. Jayamaran et al and Jha et al both implemented positive therapeutic verbal suggestions accompanying their background music selections. ${ }^{5,8}$ Another study by Santhna et al studied on the effects of postoperative music therapy using the patient's own selection of music after total knee replacement which showed a significant reduction of pain scores in patients who received music therapy. ${ }^{17}$ The varied types of music used in current music therapy research probably makes it difficult to compare results across studies.

The article by O'Challagan on complimentary therapies in terminal care summarises the mechanism of pain reductions after music/prayer recitation therapy. ${ }^{18}$ There are three proposed mechanisms which includes psychophysiological theory; spinal mechanisms involved in pain modulation (the gate control theory) and the role of endorphins. The intensity and quality of pain experienced is influenced by psychological variables which include: the memories of previous experiences; one's understanding of the origin of the pain and its consequences; cultural factors, the presence of competing stimuli (distractions) and one's level of anxiety and expectations. Music/ prayer therapy is believed to reduce pain intensity by being offered as a distraction, to reduce anxiety and aid in relaxation. Dzikir and prayer are categorised as a form of psychotherapy. It is a method for muslims to interact with Allah which contains spiritual elements, that can generate hope and confidence in a person who is sick, which in turn can boost immunity thus accelerating the process of healing. ${ }^{19}$

Listening to one's favorite music causes endorphins to be released into the bloodstream. A study by Goldstein showed that volunteer subjects who experienced "thrills" in response to their favorite music, experienced less thrills after being given a dose of the opiate antagonist, naloxone. The study concluded that there are endogenous opioids that are released in the blood stream in response to hearing a pleasant stimuli. There are an abundance of opioids receptors throughout the human body which when activated by opioids are effective in reducing pain. ${ }^{20}$ The mechanisms suggested above may explain the results of our study which showed a significant reduction of pain scores in Group A patients. However no significant reduction of pain scores were seen in Group B patients. This could possibly be attributed to the music selection used in this study. According to O'Challagan, the patient's own music selection is vital in order for the music therapy to have an effect on the patient. ${ }^{18}$

There are two limitations to this study. Firstly, no direct comparison was made between patients in Groups A and B due to sensitivities of religious faith and beliefs ('áqidah') as discussed and decided during the institutional ethics and research committee meeting. Secondly, the use of a confirmatory tool such as Near Infrared Spectroscopy would be a more objective way in monitoring the presence of auditory processes to confirm that patients are actually able to hear under general anaesthesia. ${ }^{21}$

Synderman in his article on intergrative medicine summarised that the best treatment strategy is to treat patients with scientifically proven medical therapy, provide compassion and pay close attention to patient's spiritual and emotional needs. Integrating complimentary medicine such as spiritual beliefs, prayer therapy and music therapy improves outcome of conventional medicine. ${ }^{22}$ 
In conclusion, this study showed that listening to prayer recitation intraoperatively in patients who underwent open appendicectomies under general anaesthesia significantly lowered intraoperative heart rates and postoperative pain scores as compared to the control group. Even though patients who received music therapy showed significant reduction of intraoperative heart rates, there was no significant improvement in postoperative pain scores.

Conflicts of interest - none to declare.

\section{ACKNOWLEDGEMENT}

We would like to thank Dr Mohd Syahir Abdul Rahman, medical officer, in the Department of Anaesthesia \& Intensive Care, Kuala Lumpur General Hospital for his assistance in data collection. We would also like to thank Ms. Qurratu'aini Musthafa, Science Officer in the Department of Anaesthesiology \& Intensive Care, UKM Medical Centre for her advice and assistance in the statistical analysis of our study.

\section{REFERENCES}

1. Apfelbaum JL, Chen C, Mehta SS, et al. Postoperative Pain Experience: Results from a National Survey Suggest Postoperative Pain Continues to Be Undermanaged. Anesth Analg 2003; 97:534-40.

2. Roditi D and Robinson ME. The Role of Psychological Interventions in the Management of Patients with Chronic Pain. Dove Med Press 2011; 4: 41-49.

3. Nasiri M, Fayazi S and Karimvand HK. The effects of Reciting the Word "Allah" on Pain Severity after Coronary Artery Bypass Graft Surgery. Anaest Pain Med 2014; 4: e23149.

4. Beiranvand S, Noaparast M, Eslamizade N, et al. The Effects of Religion and Spirituality on Postoperative Pain, Hemodynamic Functioning and Anxiety after Cesarean Section. Acta Med Iran 2014; 52:909-915.

5. Jha M, Ursekar R, Aphale S, et al. Effect of Music and Therapeutic Suggestions under General Anaesthesia on Postoperative Analgesic and Anti-Emetic Outcomes. IJMHS 2014; 4: 182 187.

6. Gibbison B and Kinsella SM. Postoperative Analgesia for Gynecological Laparoscopy. Saudi J
Anaesth 2009; 3: 70-76.

7. Pierre $S$ and Whelan R. Nausea and Vomiting after Surgery. CEACCP 2012; 13: 28-32.

8. Jayamaran L, Sharma S, Sethi N, et al. Does Intraoperative Music Therapy or Positive Therapeutic Suggestions During General Anaesthesia Affect the Postoperative Outcome? - A Double Blind Randomised Controlled Trial. Indian J Anaesth 2006; 50:258-261.

9. Kiviniemi K. Conscious Awareness and Memory during General Anaesthesia. AANA J 1994; 62:441-449

10. Block RI, Ghoneim MM, Sum Ping ST, et al. Human Learning during General Anaesthesia and Surgery. Br J Anaesth 1991; 66:170-178.

11. Schwender D, Daunderer M, Mulzer S, et al. Midlatency Auditory Evoked Potentials Predict Movements during Anaesthesia with Isoflurane or Propofol. Anaesth Analg 1997; 85:164-173.

12. Tsuchiya M, Asada A, Ryo K, et al. Relaxing Intraopeative Natural Sound Blunts Haemodynamic Change at the Emergence from Propofol General Anaesthesia and Increases the Acceptability of Anaesthesia to the Patient. Acta Anaesthesiol Scand 2003; 47:939-943.

13. Kahloul M, Mhamdi S, Said Nakhli M, et al. Effects of Music Therapy under General Anesthesia in Patients Undergoing Abdominal Surgery. Libyan Journal of Medicine 2016; 12 :1 6.

14. Okada K, Kurita A, Takase B, et al. Effects of Music Therapy on Autonomic Nervous System Activity, Incidence of Heart Failure Events, and Plasma Cytokine and Catecholamine Levels in Elderly Patients with Cerebrovascular Disease and Dementia. Int Heart J 2009; 50: 95-110.

15. Riganello F, Cortese MD, Arcuri F, et al. How Can Music Influence the Autonomic Nervous System Response in Patients with Severe Disorder of Consciousness? Front Neurosci 2015; 9:461.

16. Haryani A, Arifudin and Nurhayati. Prayer and Dhikr as Spiritual-Related Interventions for Reducing Postsurgical Pain Intensity in Moslem's Patients. Int J Res Med Sci 2015; 3:3035.

17. Santhna LP, Norhamdan MY and Damrudi M. The Effectiveness of Music Therapy for Postoperative Pain Control among Total Knee Replacement Patients. Med \& Health 2015; 10: 66-79

18. O'Callaghan CC. Complementary therapies in 
Terminal Care. Pain, Music creativity and music therapy in Palliative Care. In: Am J Hosp Palliat Care 1996 [online]. Available at: ajh.sagepub.com. Accessed November 15, 2017.

19. Dadang Hawari H. Al-Quran: Ilmu Kedokteran Jiwa dan Kesehatan Jiwa. Jakarta: Dana Bhakti Prima Yasa. 1998.

20. Goldstein A. Thrills in Response to music and other stimuli. Physiological Psychology 1980; 8 (1):126-129.

21. Patoine $B$. Visualizing Hearing: Brain Imaging May Improve Outcomes in Deaf Children with Cochlear Implants. Dana Grantee 2012 [online]. Available at: www.dana.org. Accessed January 10, 2018.

22. Snyderman R and Weil AT. Integrative Medicine. Bringing Medicine Back to Its Roots. Arch Intern Med 2002; 162:297-295. 
